\title{
CONSERVACION DEL ARTE RUPESTRE AL AIRE LIBRE
}

\author{
ROSARIO LUCAS PELLICER
}

En el I Congreso de Conservación de Bienes Culturales, celebrado en Sevilla (19-21 de marzo de 1.976) la ponencia de $D$. Samue1 de los Santos, Director del Museo Arqueológico Provincial de Albacete, fué una llamada de atención hacia la conservación del arte rupestre levantino (1).

Se ha hecho muy poco, por no decir nada, a este res-pecto. A nivel internacional y nacional existe una problematica candente, no concluida, sobre la conservación del arte paleolitico localizado en cuevas (2) pero sobre el arte post paleolitico ni tan siquiera se ha planteado esta problematica, al menos con el suficiente énfasis como para. całar en -las conciencias de las autoridades rectoras de nuestra cultu ra.

Indudablemente entre ambos tipos de arte el problema es distinto. Las soluciones del primero pueden beneficiar al segundo, pero'cada uno de ellos tiene sus peculiaridades especificas y requiere un trato individualizado que no puede postergarse por mucho tiempo.

Las condiciones ambientales son bien diferentes. Cual quier alteración del microclima mantenido durante cientos $y^{-}$ aún miles de años en las estaciones de arte paleolitico puede derivar en unos efectos degradantes a corto plazo si no se toman en su justo momento las medidas oportunas para equi librar la descompensación y mantener las condiciones primiti vas (3).

Las variaciones del binomio humedad-temperatura impues tas por la apertura de nuevos accesos, modificaciones internas o externas, visitas indiscriminadas, iluminación artificial, etc. influirán desfavorablemente en la estabilidad de las condiciones fisicas del interior $y$ por tanto en el sopor te $y$ en el arte, aparte de otra serie de problemas que, originados por las causas anteriores o provocados por la acción de agentes biológicos (4) concluirán fatalmente en la altera cion de la superficie rocosa y en la desaparicion de las manifestaciones artisticas, sea grabado o pintura. 
Sin embargo, el estudio y la minuciosa investigación de los agentes climáticos y lumínicos, así como sus oscila-ciones, es un problema menor dentro de los análisis e investigaciones que deben llevarse a cabo para conservar el arte de los abrigos rupestres o de las rocas al aire libre. Desde su origen estas manifestaciones artísticas han desafiado los agentes atmosféricos $y$ erosivos $y$ han llegado hasta nosotros porque han resistido los efectos degradantes de la luz solar, los cambios bruscos de temperatura, la lluvia, el viento, el frio, el hielo o el calor. Porque la roca -el soporte- y el color - elemento sustentado cuando se trata de pintura- han vencido estas adversidades que, lógicamente han marcado con su huella el paso inexorable del tiempo,pero nunca existe el impacto que sufre el arte parietal cuaternario cuando se quie bra su microclima, sencillamente porque en el arte al aire libre no existe ese microclima cerrado casi en perfecto equi librio $y$ estabilidad.

Sin embargo en uno y otro caso el trato que les dé el hombre (5) incidirá positiva o negativamente en su conservación. Aparte de cualquier acción vandálica (arrancado de la roca, desprendimiento de la capa pictórica intencionadamente, repintes, dibujos, fogatas...) que por ignorancia o maldad suele darse en muchas circunstancias, no es infrecuente que la pintura en abrigos vea acelerada su degradación a conse-cuencia del frotado con elementos húmedos para avivar el color (riesgo de arrastrar la superficie pintada o desleir los pigmentos solubles $y$ acción secundaria de las impurezas de los humectantes) o por la abrasión de los medios empleados para eliminar el polvo, suciedad o coberturas adicionales - (desprendimiento o debilitación de la superficie artística) o por el efecto calorífico y lumínico de un foco directo o intenso por más tiempo del que estos colores pueden soportar (alteración de la cohexión molecular y empalidecimiento...) acciones cuyos efectos físico-mecánicos y químicos recaen so bre la debilitada naturaleza de estos elementos a la intempé rie sometidos a la constante agresividad de los factores ambientales.

Los especialistas modernos no ignoran todos estos ries gos $y$ hoy nadie en un estudio científico se atrevería a usar tales métodos pero, por desgracia, los estragos causados por móviles humanos, o bien son hechos consumados, o pueden repe tirse por imprudencia e ignorancia.

La defensa contra esta acción humana no sólo está en la salvaguarda de los sitios como parte integrante del Patri monio Artístico y Cultural mediante una normativa apropiada, no siempre iácil de llevar a cabo (rejas, guardas, control de visitantes...) sino en la concienciación de los individuos - 
por medio de una educación social que no se improvisa.

EI daño potencial ocasionado por las razones antedi-. chas rebasa toda dialéctica e intento de conservación. Por tanto, contra este agente humano, nocivo y latente en toda circunstancia y ante cualquier tipo de monumento, las medi-das preventivas siempre serán insuficientes porque la acción y el efecto son imprevisibles, a no ser que se arbitraran -unas leyes drásticas de propiedad y vigilancia estatal que impidieran el acceso descontrolado a todos estos lugares.

Dejando a un lado este factor harto conocido $y$ que no por más frecuente es menos digno de atención, quiero centrar me principalmente, en los factores endógenos y exógenos de carâcter previsible.

\section{Agentes internos}

E1 más importante es la naturaleza y estructura de la roca, estado actual como consecuencia de la degradación secu lar y características (tendencia al desmoronamiento, desinte gración, exfoliación, etc). Circunstancias que junto con su composición han de determinarse para comprobar su resisten-cia y escala valorativa en el tiempo (estabilidad, trasforma ciôn, tendencias de presión, higroscopicidad, capilaridad, condensación, contracción, dilatación, lesiviación... y por supuesto la reacción de los diversos componentes que integran la piedra y su comportamiento ante el ataque de los factores externos).

A este respecto existe una marcada diferencia entre las rocas con arte a pleno aire (principalmente metamórficas: granitos, esquistos...) conteniendo insculturas o grabados y los abrigos rupestres en su mayoría de naturaleza caliza en donde se albergan las pinturas protegidas en parte por la topografia del sitio. Justamente esta diferencia material im pone ya, en origen, aunque pueden hallarse salvedades, 1 a di ferencia de tratamientos en la conservación (6).

otro factor interno unido al anterior es la propia pe culiaridad de la manifestación artística. En el caso de noexistir elementos extraños a la naturaleza rupestre (caso - del grabado o técnicas afines) su suerte irá ligada a la rcsistencia del soporte $y$ a la intensidad de la técnica, más o menos vulnerable a los agentes exógenos. Cuando se trata de pinturas, las particularidades del color (penetrabilidad o ad hesión, grado de mineralización, solubilidad de los ingredien tes... tendencia a la inestabilidad...) serán otros tantos factores que incidirăn sobre los elementos sustentados aún cuando el soporte permaneciera en perfecto equilibrio de auto 
conservacion.

\section{Agentes externos}

A las causas endogenas, inherentes a la materialidad del contenido y potencialidad, se une la acción y efectos de los agentes extrínsecos que favorecen esa tendencia inesta-ble y que son el motor de las interacciones. Interacciones que cuando son de orden climatico, han sido, en cierto modo, las responsables de la propia conservación ya que si han oca sionado la pérdida de las sustancias orgánicas, han favorecí do la mineralización y fosilización del color gracias a cuyas características podemos hoy contemplar y estudiar la pintura rupestre. Pero estos mismos agentes son a su vez la causa del deterioro del soporte (7) y su alteración paulatina si no se condiciona a tiempo, acelerará progresivamente su destrucción con las incidencias derivadas sobre las pinturas cuya natura leza sufre, igualmente, el lento deterioro del tiempo, agravado cuando otro tipo de agentes rompe su ritmo secular.

A los efectos físicos y químicos de los factores climáticos hay que sumar la acción de los elementos bióticos -. presentes en todo medio ambiente. Los micro y macrovegetales que proliferan en las rocas producen, aún en caso de no ruptura, manchas, pigmentaciones y una lenta acción degradante, tanto más grave cuanto más afecten a las manifestaciones artísticas o tiendan a confundirse con ellas. La presencia de microorganismos es muy frecuente en las rocas poco protegi-das en donde la simple orientación y la existencia de zonas sombrías puede provocar un ambiente apto para el desarrollo de organismos vivos tan peligrosos y rebeldes como el propio cáncer humano (8).

otros factores biológicos alterativos son imputables a los animales. Aparte de la frecuencia esporádica o perma-nente de ganado, de la existencia o no de roedores, etc. es habitual que los insectos (abejas, avispas, escarabajos...) elijan su habitat en ciertas partes de la roca. Al daño físi co-mecánico de sus actividades se une la acción química de sus funciones y residuos, comparables en nocividad con 1a -huella y excrementos dejados por 1 as aves que, por 10 gene-ral, resultan tremendamente perjudiciales.

En resumen, aún sin contar con las graves alteracio-nes motivadas por el trato del hombre o por su intervención en el medio ambiente, contaminando la atmósfera y quebrando las condiciones primitivas, factores de índole geológica, -climática y biológica (ecología en general) influyen directa mente en la conservación y degradación de este arte, cuyas : 
interacciones y repercusiones destructoras tienen que identi ficarse en cada caso concreto para que sean analizadas minuciosamente si queremos que las manifestaciones rupestres al aire libre sigan formando parte del Patrimonio Cultural y -. puedan legarse a las generaciones futuras sin mayor daño que el ya ocasionado.

Es decir, el primer paso para conservar y prolongar la vida del arte rupestre al aire libre es defender la integridad del soporte, respetando su estado actual si este es бptimo o acusa marcada estabilidad, previniendo el deterioro mediante el control oportuno de los efectos, dirigido tan to a la zona ocupada por los dibujos o pinturas como a la tō talidad del conjunto. Puesto que la piedra forma un todo indivisible con el arte, el cambio, debilitamiento o trasforma ción estructural, repercutirá indefectiblemente en el resto, si no como hecho material, al menos como documento cientifico de integridad potencial.

En esta defensa se puede incluir, si fuera necesario, sustancias extorsivas que impidan el desarrollo de flora $y$ microorganismos o repelan la presencia animal y todo agente bibtico digno de tenerse en cuenta.

La segunda vertiente del proceso ha de polarizarse, necesariamente, en la integridad del propio arte. Si se trata de grabados la prevención vá implicita dentro del soporte ya que, al no existir otras materias incorporadas, forma un solo cuerpo y el desgaste de la incisión o profundidad del surco sera ya irreversible. Unicamente hay que impedir la -aceleracion del proceso al realizar calcos y tomar documenta cion gráfica, evitando la intervención de materiales que prō voquen reacciones imprevisibles $y$ adoptando sistemas inocuos que no comporten huellas ni residuos.

En las pinturas hay que pensar que, en origen, exis:tieron unos componentes $y$ aglutinantes capaces de fijar el color a la roca y responsables de su permanencia al correr de los tiempos.

El tema de la composición de colores ha sido y es objeto de estudio siempre que se trata de pintura rupestre. Co nocer la naturaleza y proporcion de los ingredientes es muy dificil por no decir imposible. Las sustancias organicas han desaparecido $0^{\circ}$ se han mineralizado activando la reaccion, ya mencionada, que, si limita el conocimiento, asegura la con-servación al trasformar los cuerpos orgánicos pérecederos en elementos inorgánicos más persistentes, aunque sea a costa de la pérdida de las primitivas propiedades y caracteristi-cas.

Estas caracteristicas están en función del cromatismo 
(palidez u oscurecimiento) del brillo (opacidad) y del enlace con la roca (desprendimiento). En realidad sobre este último extremo influye tanto 1 a autodegradación como el grado cuantitativo de penetración o el alcance cualitativo del con tacto entre soporte $y$ materia sustentada, valores imputables a los componentes y proporción y por tanto subordinados al origen $y$ no a las circunstancias.

Normalmente cuando se realizan análisis sobre muestras pictóricas, la capa de pintura se halla intermedia entre la roca y una capa superficial de $\mathrm{CO} 3 \mathrm{Ca}$ (9). Las macrofotografías muestran la película de concreción a base de carbonato calcico recubriendo el color cuyos simples ensayos detectan, sobre todo en los rojos, pigmentos de óxido de hierro sin que se pueda decir mucho más.

Lógicamente esta capa de carbonato câlcico, más o menos impura, es un elemento intrusivo ajeno a la primitiva in tencionalidad. El tiempo y la reacción química de los diversos elementos cobran asi su tributo a los siglos. El color original queda empañado y hay ausencia de brillo. Si la capa es un simple "velo" permitirá identificar y seguir los tra-zos; si es más gruesa o impura el color se adivina pero es practicamente irreconocible el limite y conformación del dibujo y en ocasiones queda completamente anulado.

Otras veces la solubilidad de los diversos componen-tes liticos pueden acarrear manchas superficiales (oxidación y reducción de sustancias férricas) más o menos oscuras, sales, disoluciones... con efectos más perjudiciales que la ca pa de carbonato cálcico que, hasta cierto punto, puede ser una potrección. Asímismo 1a pigmentación, acidez y ataque en general de elementos vegetales, residuos y excrementos anima les derivan en veladuras, capas $y$ auténticas costras que es conden los dibujos y deterioran su naturaleza al igual que sucede con la formación de estalagmitas en contados ejemplos - con la huella del humo y fogatas tan abundantes en nuestros abrigos.

Estos mismos daños junto con craquelación, desintegra ción o desprendimientos, pueden surgir también como consecuencia de la combinación de acciones entre el soporte y la zona pintada, cuando se ha abusado del realzado del color o existen esas manipulaciones humanas tan justamente censuradas.

En cualquier caso siempre que el dibujo sea reconocible podrá realizarse el estudio, pero si existen deficiencias es casi una obsesión de todos los investigadores (sin mencio nar el gran público) hallar el modo más eficaz de reavivar el color, especialmente con vistas a obtener calcos fidedignos y fotografías documentales. Desgraciadamente, bien por - 
esta suerte de causas naturales o por los sistemas de reavivado poco escrupuloso, ha podido llegar el desenlace fatal de la disminución o pérdida del color con el daño consecuente que podemos considerar irreparable.

Es lógico que, consecuentes del problema, se busque una solución y no se impida el avance investigador por todo este cúmulo de causas, dejando al estudioso cargado con una serie de prejuicios pero sin respuesta adecuada para paliar las limitaciones del trabajo y sobre todo, a nivel futuro, que no seamos pasivos ante algo que es inevitable a muy corto plazo: 1a pérdida de todas o gran parte de estas manifestaciones artísticas sometidas a las más diversas adversidades.

Teniendo presente 10 antedicho 1a problemática se cen tra en tres puntos principales: a) conservación del soporte; b) conservación de los dibujos; c) recuperación de la pintura o del grabado cuando se hallen ocultos o distorsionados.

\section{Conservación del soporte}

Sobre este primer aspecto en el que ya he insistido, el trabajo, tras analizar la naturaleza de la roca y determi nar causas, efectos y escala de degradación, es de prevención y debe dirigirse a la limpieza y consolidación de la roca em pleando sistemas y medios idénticos o similares a los ya experimentados en otro tipo de bienes culturales inmuebles que permanecen al aire libre (10). Es decir 1a conservación es viable si se parte de un estudio científico de la materia y de las condiciones ambientales y se aplican los procedimientos hoy vigentes para controlar la alteración y las circunstancias negativas. A ésto hay que agregar una severa legisla ción sobre los lugares y la fiscalización de trasformaciones en la zona de emplazamiento e incorporación de elementos per judiciales (fábricas, industrias contaminantes, pantanos, carreteras, desmontes...) que alterarian la estabilidad del medio y del paisaje variando el carácter primitivo del área geográfica que con toda probabilidad influyó en la elección del lugar y en las circunstancias que rodean la motivación de este arte y su conservación. Revisiones periodicas progra madas impedirian o erradicarían a tiempo los efectos bióti-cos degradantes.

\section{Conservación del arte}

Respecto al grabado, cuanto se ha dicho a cerca del soporte y el cuidado en la obtención de documentación cientí 
fica, es válido para conservar. Si se trata de pinturas, tras analizar condiciones del soporte y del color, el sistema a . emplear, aparte de ser adecuado, compat'íble, estable y duradero, tiene que activar el cromatismo con garantia de otras complicaciones posteriores, para impedir de esta forma que se recurra a otros medios en su estudio y reproducción. Tam biến en este campo existen tratamientos y productos de larga experiencia (11) especialmente sintéticos que pueden resol-ver el problema sin demasiadas complicaciones $y$, 10 que es más importante, sin alterar las caracteristicas primitivas, garantizando su reversibilidad si fuera necesaria su futura eliminación y sin derivar en seudeproblemas.

No obstante haciendome eco de la discusion en el aludido Congreso tras la intervención del $\mathrm{Sr}$ de los Santos, :quiero recalcar una cuestión que parecía de sumo interés: 1a toma de muestras para realizar estos ensayos. A nivel de los profesionales en conservación y restauración, la toma de mues tras en este y otros objetivos es una tarea rutinaria, sometida a criterios fijos (al igual que todo trabajo de conservación y restauración) que sólo pueden ignorar los temerarios de dudosa profesionalidãd. Este muestreo no ofrece riesgo al guno especialmente si se tiene en cuenta los beneficios que su exámen puede reportar (solubilidad de pigmentos, resisten cia, compatibilidades...) a la hora de seleccionar el tratamiento. Si queremos que la labor sea cientifica y garantizable hemos de exigir estos ensayos que pueden, incluso, obtenerse sin tocar en absoluto el contenido actual. En ocasio-nes basta con observar al pie de los abrigos los pequeños 0 grandes trozos desprendidos de la pared en los que, por desgracia, no es dificil hallar la existencia de color. En caso contrario habrá que arrancar a la roca ese mínimo pedacito de superficie coloreada en una zona inocua o con riesgo de desprendimiento inminente y que bastará para realizar el test sin pérdida alguna de la integridad total. Es más, en caso de mayor peiligro sería posible, debidamente programados, ap1i car "in situ" análisis no destructivos (isótopos, fluorescen cia, rayos $X \ldots$ )

Si estas comprobaciones se realizaran, los arqueб10-gos tendríamos científicamente amplias compensacioutes, no s61o por la conservación de las pinturas con medios idóneos individualizados, sino porque los anlisis permitirian obtener tablas de colores, ingredientes y composición, parangona bles con los resultados de analizar masas de color si las -hay o de otros colorantes posibles, como ciertas rocas de -los abrigos o sus alrededores (análisis por activación) o de sustancias orgánicas (cromatrografía, electroforesis...), .que sometidas a envejecimiento artificial y en determinadas 
condiciones llevarian a resultados insospechados, sobre todo si se aplica una investigación altamente especializada en -combinación con diversos sistemas de trabajo y con una orien tación práctica por parte de los arqueólogos (12).

\section{Recuperación de la pintura o grabado}

Finalmente la recuperación de las zonas ocultas, perdidas o enmascaradás, tal vez sea el punto más delicado. La aplicacion de rayos ultravioletas, infrarrojos o sistemas $s i$ milares (13) para detectar colores o pigmentos desaparecidos, invisibles al ojo humano pero susceptibles de captar por métodos técnicos podría ser el medio más eficaz (al igual que 10 sería para captar o discernir las zonas excesivamente empalidecidas o debilitadas, repintes, superposiciones, etc.). Los resultados de estos sistemas aunque aparentemente teóricos, están bien confirmados al igual que sus ventajas y su daño si no se emplean adecuadamente. La inconveniencia radica, hay que ser conscientes, en que por tratarse de soportes no trasportables, los medios han de ir al objetivo y no vice versa $y$ este objetivo, dada su ubicacion, es realmente dificil de alcanzar porque requiere un equipo complejo y una ser vidumbre energética de considerable potencia.

La eliminación de concreciones, coberturas y manchas de todo tipo es compleja. La fragilidad de la pintura y la resistencia $y$ rebeldia de los agentes destructores implican la utilización de disolventes enérgicos en sus efectos peró suaves $y$ lentos en su actuación $y$ siempre controlables e ino cuos respecto al color y a la roca. Productos en suma que no se improvisan $y$ requieren la selección y búsqueda del trata miento más ventajoso $y$ positivo.

También se pueden emplear medios mecánicos (14) pero personalmente casi me atrevo a descartarlos, a no ser que se trate de capas muy gruesas donde "a priori" ni pintura ni so porte se verían afectados al iniciar el trabajo que, necesariamente tendría que combinarse con el empleo de disolventes rigurosamente experimentados. (Los restos de humo presentan una complejidad extrema. Dada la inercia química ante ácidos y álcalis y la marcada estabilidad del carbono, 1a efectividad de los disolventes es muy problemática $y$ por tanto los procedimientos mecánicos parecen los más positivos a pesar del riesgo que implica acudir a tales sistemas).

Cuando se trata de grabados el problema se centra en erradicar las materias parásitas que ocultan los dibujos e impiden la visibilidad. En rocas metamorficas se pueden eliminar los elementos intrusivos siempre que se disponga de me 
dios adecuados manejados con precaución (cepillos de fibra de vidrio o nylon) o se ablande la superficie con una so lución diluída en amoníaco (15) si no existe riesgo de desiñ tegracion. Esta operacion simple conviene que sea comprobada previamente y que esté a cargo, al igual que todos 10 s proce dimientos anteriores, de personas diestras en estos trabajos que a su vez podrán tratar la superficie con el sistema más útil, a fin de inocular y repeler, tras los análisis de ri-gor $y$ el asesoramiento técnico pertinente, los elementos bio ticos que tiendan a proliferar. Si el problema es más gravé se impone un estudio profundo de causas $y$ efectos para inves tigar, en consecuencia, el modo de combatirlos sin derivar en accidentes secundarios o en soluciones más perjudiciales a largo plazo.

No obstante, a pesar de todos los inconvenientes $y$ de la complejidad de ios problemas hay algo que está claro: el arte rupestre al aire libre no está exento de riesgos: Si existe debe prevenirse el daño, controlar la degradación y adoptar cuanto antes las medidas preventivas (tal vez limpie zas periodicas serian suficiente en una gran parte de esta-ciones) con los análisis necesarios para iniciar, sin demora, la conservación e impedir que se abandone al azar o a la mera casualidad la permanencia y durabilidad de estos valiosos documentos.

No está en manos de arqué́logos o prehistoriadores -llevar a cabo el trabajo; existen cientificos y técnicos en la materia $y$ centros especializados; los objetivos son via-bles. A los arquélogos corresponde reclamar esa atencion, hacer oir sus voces $y$ fomentar en los expertos $y$ en las auto ridades el interés por investigar la conservación, prevención, limpieza y consolidación, si es necesario, de todo este arte rupestre, quizá menos espectacular que el paleolítico pero no menos valioso. A una conciencia sobre el estado actual de desamparo de la gran mayoría de estos lugares hay que promocionar un metбdico y sistematico programa que informe sobre el estado de conservación, peligrosidad, factores, efec tos, etc. y que sea precedente de esa actuación posterior ..que tan grandes beneficios puede reportar.

Con estas lineas me hago eco de la llamada ante los especialistas en conservacion de materiales inorgánicos y a sus grupos de trabajo, pues pienso que por destinarse esta revista a los profesionales de Prehistoria y Arqueología pue de calar en el espíritu de los interesados en este campo y aunar nuestros esfuerzos. Quiero aclarar que yo soy lega en estas cuestiones aunque es un mundo en el que por circunstan cias personales estoy indirectamente vinculada $y$ cuento con 
una larga experiencia sobre centros, métodos de trabajo, debates, realidades alcanzadas y perspectivas futuras. Por estas razones soy consciente del problema, de la profesionalidad de nuestros técnicos y de la solvencia de los medios y por consiguiente de la garantía del trabajo, que sólo puede plantearse y ser una realidad cientifica, a nivel de problema individualizado dentro de una investigación conjunta, en perfecta armonia y consenso entre las partes implicadas.

No obstante, como primera aportación de urgencia y an te la carencia de medidas más solventes, especificas para es te objetivo,puedo aconsejar unds primeros auxilios cuya expe riencia ya consumada permite un cierto aval en los resulta-dos (16) aunque insisto en que esta exposición no tiene otras pretensiones que guiar la limpieza y consolidación superfi-cial de las rocas más deleznables y en peligro de exfoliación o desprendimiento $y$ proteger las pinturas en avanzado estado de alteración y debilidad. En suma, para orientar al investigador a cerca de las medidas a tomar ante casos extre madamente graves o ante el dilema de realzar el color. Ojalá estas consideraciones promuevan una reacción y a esta simple iniciativa se sumen trabajos más ortodoxos $y$ se adopten medi das más reales que la simple letra impresa.

\section{Limpieza}

E1 polvo superficial se puede eliminar con brocha de pelo suave que no infrinja arañazos ni raspados en la superficie pintada. Si la operación se hace con las debidas pre-cauciones el efecto mecánico es imperceptible. También puede emplearse el pincel que usan los fotógrafos para limpiar los objetivos $y$ que dispone de un sencillo mecanismo que absorbe el polvo que se va desprendiendo.

\section{Eliminación de concreciones calizas}

En casos débiles puede obtenerse buenos resultados - aplicando por pulverización agua acidulada a base de ácido clorhídrico o acético en proporción 1 a 5 por 1.000 . Aunque existen muchos ácidos que pueden ser útiles, los seleccionados son los más débiles de todos los ácidos fuertes $y$ por - tanto el riesgo de daño es infinitamente menor que cualquier otro sistema no analizado previamente. Tras esta aplicación debe lavarse la superficie con agua desionizada, siempre pul verizando. Es aconsejable practicar una prueba en alguna zona libre para determinar sí la proporción es correcta. 


\section{Consolidación y fijado de color}

Tras la limpieza en seco o en húmedo pueden aplicarse productos tales como Mowilith, Paraloid, Nylon soluble (Kala ton)... diluídos en sus disolventes específicos en proporción del 5 a $10 \%$ (acetona para el Mowilith; nitro para el Paraloid $y$ alcohol si se ha elegido el Nylon soluble en cuyo caso se efectúa la disolución a una temperatura de 20 a $25^{\circ} \mathrm{C}$ ). Por su fácil manejo, adquisición y estabilidad a la intemperie son aconsejables el Mowilith y el Paraloid, fijativos alta-mente experimentados (17).

La emulsión, en cualquier caso, debe efectuarse en ca pas sucesivas incrementando e1 tanto por ciento en la dilu-ción (más débil al principio y con mayor concentración al fi nal) con objeto de evitar la fuerte conexión de moléculas y el consiguiente perjuicio de arrastre o desprendimiento por tensión excesiva. Es obvio que no se aplicará una capa tras otra sino después de que esté seca la anterior.

Este sistema puede aplicarse indistintamente a zonas pintadas o a rocas exfoliables o descorchadas para impedir su desintegración o desprendimiento sucesivo.

Todos los productos mencionados han sido reiteradamen te comprobados $y$ utilizados en problemas similares y circuns tancias parecidas (18) siempre con resultados positivos, ya sea sobre materia orgánica, inórganica o se trate de pigmentos solubles o insolubles. Entre sus principales caracteristicas destacan:

a) Probada estabilidad físico-química sin producir de rivaciones ni alteración de color. Poseena la vez intensa pér manencia.

b) Acentuado indice de refacción que permite una visi bilidad mayor en la zona tratada.

ción.

c) Facilmente reversibles si se estimara su elimina-

Es decir, el poder aislante de todos estos productos impide la degradación paulatina del color, tanto frente a la acción luminica como ante el abuso humano de restregar con agua figuras y colores. A su vez esta finisima pelicula de recubrimiento, invisible al ojo humano, totalmente trasparen te $y$ que acentúa el cromatismo permite que la pintura, sin = perder ninguna de sus propiedades, se aprecie con mayor niti dez. La pelicula aislante y protectora evita que la superficie reciba el impacto de los agentes erosivos, del polvo y de todos los restantes agentes exógenes que ante la ausencia 
de una defensa adecuada actúan directamente sobre las mani- festaciones artísticas. Su acción, en suma y salvando las -distancias, es comparable con el barniz protector de los cua dros y por consiguiente susceptible de ser retirado por me-dio de su propio disolvente si fuera necesaria, por circunstancias imprevistas, su eliminación o sustitución.

A la par que tiene estas ventajas, el poder consoli-dante evita, inclusive, el desprendimiento de la roca, forta leciendo las partes débiles y las zonas más vulnerables a la caída o a la pérdida paulatina de la superficie rocosa.

Insisto, una vez más, que estos consejos son válidos únicamente para emergencias y por tanto no tienen otras pretensiones que suplir, la carencia de medidas previamente ana lizadas $y$ adecuadas especificamente a un objetivo particularizado. Medidas que como se ha dicho sбlo podrán ser reali-dad cuando el problema se plantee a nivel de un programa sis temático de preservación con el consenso y orientación con-junta entre expertos en la conservación de Bienes Culturales y los propios arquélogos.

NOTAS

(1) S. de los SANTOS: La conservación de las pinturas rupespestres en los abrigos del Levante Españo1. "Actas del I. Congreso de Conservación de Bienes Cul turales" Sevilla, 1976, pág. 3

(2) E1 cierre de Altamira en noviembre de 1.976 y 1 a forma-cion de un Comite encargado de investigar su conservación son buena prueba de 1a complejidad existente $y$ de la honda preocupación por afrontar el problema.

(3) COREMANS, P.: Clima y microclima en "Conservación de los Bienes Culturales", UNESCO, 1969, påg. 31 a 44.

(4) Vide nota anterior pág. 34 y R. HEIM y otros: Lucha contra los mohos... Ibídem, especialmente pág. 55.

(5) Op. cit. nota 1 y A. BELTRAN: Arte rupestre levantino, Zaragoza, 1968, pág. 14-15.

(6) PLENDERLEITH, H.J. Monumentos: Problemas de Preservación en "La Conservación..." ob. cit. pág. 134-149. 
SNEYERS, R.V. y HENAU, P.J.: La conservación de la piedra Ibídem, pág. 223-250.

(7) Ob. cit. nota 3

(8) Vide nota 4 .

(9) He de agradecer a D. J.M ${ }^{a}$. Cabrera del I.C.R.O.A. el análisis que a este respecto realizb sobre las muestras de las pinturas del Barranco del Durantón (Segovia). Resultado que se une a los muchos obtenidos ya al estudiar otras pinturas rupestres dentro $y$ fuera del área peninsular.

(10) PLENDERLEITH,H.J. y SNEYERS, R.V., citas nota 6. Véase -también CABRERA, J.M.: Álteración y conservación de los materiales pétreos en los monumentos históricos "Euadernos de Prehistoria y Arqueologica", $\mathrm{N}^{\circ} 2$, Madrid, 1975, pág. 55-77 (Síntesis Tesis Doctoral).

(11) PHILIPPOT, P y MORA, P.: La conservación de pinturas murales en "la conservación..." ob. cit. păg. 181-202yApêndice final: Materias sintéticas empleadas en 1a conservacion de bienes culturales (recop. y rev. por M. TORROCA, păg. 321-334.

(12) PESCE, ROSE y PASBY: Fluoreseence spectroscopy, Dekker, 1971.

CALVERT y PITTS: Photochemystry, Wiley, 1966.

KRUGER, J.: Instrumentation in applied nuclear chemistry New York, 1973.

(13) CROUTHAMEL, C.E.: Applied Gamma-Ray spectrometry, Oxford $1970,2^{\mathrm{a}} \mathrm{Ed}$.

ZIEGLER, Ch.: Aplication of low energy $X$ and gamma Rays, New. York, 1971.

(14) Ob. cit, nota 10

(15) SNEYER, R.V. y HENAU, ob cit. pág. 242.

(16) El sistema se aplicó en algunas localidades rupestres dẹl Barranco del Duratón con resultados óptimos.

(17) TORROCA, M.: Materiales sintéticas empleadas en 1 a conservacion de Bienes Culturales, en "La Conservacion.." ob. cit. pag. 321 y ss.

(18) En la sede central de la UNESCO, en Paris, existe un banco de datos bibliográficos a disposición de quienes requie ran su consulta o soliciten información sobre determinado aspecto. 